\title{
Apontamentos para uma análise das representações de Getúlio Vargas estampadas na Revista do Rádio (1948-1950)
}

\author{
Maycon Dougllas Vieira dos Santos \\ Mestrando do Programa de Pós-Graduação em História Social da Universidade de São \\ Paulo (USP)
}

\section{Resumo}

O presente trabalho tem por principal objetivo analisar a construção da imagem de Getúlio Vargas retratada na Revista do Rádio, semanário especializado em assuntos radiofônicos. O recorte temporal para esta análise se detém no período da campanha presidencial de 1950. A revista estampou em seus editoriais retratos de Vargas quase sempre "bem-humorado", contribuindo para que o antigo ditador fosse representado como uma figura carismática. $\mathrm{O}$ semanário também publicou diversas entrevistas com artistas de rádio que deixavam bem claro que nas eleições votariam em Vargas. Caminhando na esteira da historiadora Tânia Regina de Luca, que nos diz que "a imprensa periódica seleciona, ordena, estrutura e narra, de uma determinada forma, aquilo que se elegeu como digno de chegar até o público", temos por hipótese que a Revista do Rádio, mais especificamente seus editores, alinhados política e ideologicamente às ideias e ao projeto defendido pelo varguismo, construiu, de forma coesa e precisa, a imagem positiva de Vargas, apresentando ao seu público (e)leitor em quem deveriam votar, bem como qual projeto político deveria vigorar no cenário político nacional.

Palavras-chave Revista do Rádio - Getúlio Vargas - Imagem e representação.

\begin{abstract}
The present work has as its main objective to analyze the construction of the image of Getúlio Vargas portrayed in Revista do Rádio, a weekly magazine specialized in radiophonic subjects. The time frame for this analysis pertains to the period of the 1950 presidential campaign. The magazine printed portraits of Vargas in its editorials, almost always "good-spirited", contributing to the former dictator being represented as a charismatic figure. The magazine also published several interviews with radio artists who made it very clear that in the election they would vote for Vargas. Following in the footsteps of historian Tânia Regina de Luca, who tells us that "the periodic press selects, orders, structures and narrates, in a determined way, that which was elected as worthy of reaching the public", we have the hypothesis that the Revista do Rádio, more specifically its editors, politically and ideologically aligned with the ideas and project defended by the Varguismo, built, in a cohesive and precise way, the positive image of Vargas, presenting to its audience of readers-voters who they should to vote on, as well as which political project should be in force on the national political scene.
\end{abstract}

Keywords Revista do Rádio - Getúlio Vargas - Image and representation. 
Submissão

$05 / 09 / 2020$

Aprovação

I9/10/2020

Publicação

$07 / 12 / 2020$

\section{Introdução}

$\mathrm{O}$ período que abarca desde o fim do Estado Novo até o golpe militar instaurado em 1964 é usualmente conhecido, e compreendido pela historiografia brasileira, como a maior experiência democrática até então conhecida e vivenciada no cenário político nacional. Tanto no sentido quantitativo, pois o número de eleitores aumentou exponencialmente, quanto no sentido qualitativo, por assim dizer, pois após is anos com Getúlio Vargas no poder, o país passaria a pôr novamente em prática o exercício eleitoral. Conforme Douglas Souza Angeli, o novo desenho do corpo eleitoral, que começara a ser delineado ainda em 1945, integrou as classes trabalhadoras urbanas, o que contribuiu para que o número de votantes fosse ainda maior. Ainda segundo Angeli,

Se a participação eleitoral do proletariado surgido da industrialização brasileira do início do século XX era limitada por um sistema eleitoral restritivo, a legislação elaborada nos últimos meses do Estado Novo, em 1945, foi desenhada com o objetivo de reconhecer o direito ao sufrágio dos trabalhadores das zonas urbanas. ${ }^{1}$

Todo o aparato burocrático-administrativo montado para garantir a legitimidade de Vargas no poder foi sendo, gradualmente, desestruturado, assim tornando os eixos econômicos, sociais e políticos livres e independentes do aparelho estado-novista, que caíra acompanhado de seu maior representante. No entanto, para tomar emprestadas as palavras de Jorge Ferreira, "cai a ditadura do Estado Novo, mas cresce o prestígio do ditador". ${ }^{2}$ Esse prestígio pode ser constatado por conta dos enfáticos momentos e movimentos do pós-Estado Novo, dentre eles, o "queremismo" que reivindicava, principalmente, a continuidade de Vargas no cargo presidencial; a fundação do Partido Trabalhista Brasileiro (PTB), criado e organizado pelas bases sindicais ligados ao

I ANGELI, Douglas Souza. "Do populismo à experiência democrática: a incorporação dos trabalhadores urbanos ao cenário político brasileiro”. In: Estudios Históricos, Uruguai, n. 17, 20ı6, pp. I-23. Citação à pág. 7 .

2 FERREIRA, Jorge. “Quando os trabalhadores 'querem': política e cidadania na transição democrática de 1945”. In: História Oral, n. I, 1998, pp. 169-193. Citação à pág. I69.

I88 • ano XI, n. 16, $2020 \cdot \mathrm{ISSN} 2 \mathrm{I} 79-5487$ 
Ministério do Trabalho; por fim, o retorno do próprio Vargas à presidência do país, em 1951, eleito democraticamente.

A imprensa brasileira nesse período não só estava "respirando novos ares", como também se viu livre dos mecanismos de controle e censura impostos pelo antigo Departamento de Imprensa Propaganda. Assim como também participara ativamente das discussões políticas vigentes, opinando e até mesmo orientando seus leitores a despeito das eleições, partidos e preferências desse ou daquele político. Luis Ricardo Araújo da Costa, dissertando sobre o papel da imprensa carioca na campanha presidencial de Vargas, nos diz que há uma "compreensão de que a imprensa brasileira vinculava-se, à época, a um jornalismo com posições políticas sensivelmente clarificadas". ${ }^{3}$

Dentre os mais variados tipos de imprensa que havia naquela época, gostaria de trazer para esta análise a Revista do Rádio, criada em 1948 e que tinha por editor-chefe Anselmo Domingos. Como o nome da revista sugere, os assuntos em que o semanário se detinha estavam plenamente relacionados ao universo radiofônico. Porém, apesar de ser uma revista especializada em rádio, a mesma não deixou também de participar do debate político. Isso pode ser vislumbrado já nos primeiros números da revista, onde se revela um sentimento de saudosismo do tempo de Vargas no poder. No entanto, deixaremos para tratar dessa questão nas próximas linhas. O que pretendo evidenciar desde já é que havia certo alinhamento ideológico entre o projeto defendido pelo varguismo e as pretensões políticas dos “trabalhadores do rádio".

Logo, o principal objetivo deste trabalho é analisar a construção da imagem e das representações de Getúlio Vargas estampadas nos números que acompanharam o período da campanha eleitoral até o retorno à presidência. Como existia uma intrínseca relação de Vargas com os artistas de rádio, bem como havia uma grande pretensão destes últimos em participarem do jogo político, os editores da revista não mediram esforços para construir, de maneira coesa e positiva, a imagem carismática de Getúlio, contribuindo para que "o retrato do velho fosse colocado outra vez". ${ }^{4}$

Minhas intenções também giram em torno de evidenciar as razões que levaram os artistas de rádio a apoiarem Getúlio, e se esse apoio contribuiu para que eles tivessem maior chance de adentrarem o campo político. A proposta é tentar perceber a

3 COSTA, Luís Ricardo Araújo da. Bota o retrato do velho outra vez: a campanha presidencial de I950 na imprensa do Rio de Janeiro. 20I4. Dissertação (Mestrado em História). Universidade Federal Fluminense. Niterói. 20I4., I86 págs. Citação à pág. Io.

4 Nas eleições de 3 de outubro de 1950, quando Getúlio Vargas voltou à presidência da República por via democrática, a trilha-sonora da vitória foi uma marchinha de carnaval. "Bota o retrato do velho outra vez, bota no mesmo lugar”, repercutindo a composição de Haroldo Lobo e Marino Pinto lançada por Francisco Alves - após gravação realizada em I6 de outubro de 1950, na Odeon. 


\section{REVISTA ANGELUS NOVUS}

construção da imagem de Getúlio Vargas para além das próprias estruturas narrativas e imagéticas que a revista publicou sobre ele. Compreendendo que as representações tentam convencer a audiência de que o mundo, a sociedade, e certamente, a política são exatamente o que elas dizem que são (como prevê a noção de representaçãos cunhada por Roger Chartier), interessa saber como o uso coeso das imagens positivas do então ex-ditador foi tramado para determinados fins políticos, que beneficiavam não só Vargas, mas toda a comunidade de radialistas que estava pleiteando cargos políticos na época em questão.

\section{Revista do Rádio: história, trajetória e aspectos políticos}

A Revista do Rádio foi uma das maiores revistas especializadas em assuntos radiofônicos de sua época. A revista contava com, normalmente, so páginas; a capa geralmente vinha com fotografias de artistas de rádio, principalmente mulheres; e seu conteúdo vinculava-se integralmente a assuntos referentes ao rádio. Tinha por diretorchefe Anselmo Domingos, escritor e roteirista de radionovelas da época. Ele escreveu, na primeira edição da revista, ao falar dos objetivos do semanário, que "programa não apresentamos. Ele está encerrado no próprio nome da revista. Estaremos cumprindo um programa se cumprirmos com o título". ${ }^{6}$ Logo, seguindo à risca o que é proposto pelo editor-chefe, a revista destinava-se a tratar de assuntos integralmente relacionados ao rádio.

Percorrendo então o primeiro número que fora publicado, esta não viera com sumário, por exemplo, ao certo por não ter ainda as colunas bem definidas. Muito nos chama a atenção a coluna sobre teatro, onde Olavo de Barros, que havia sido convidado por Anselmo para tomar conta desta, o persuadiu no meio de seu serviço na rádio Tamoio. Olavo apresenta como fora o diálogo com o diretor da revista, mostrando, assim, como ainda estavam sendo trilhados os primeiros passos, colunas, notícias, fofocas e o universo dos artistas de rádio e suas respectivas formas de organização na revista.

Doris Fagundes Haussen e Camila Stefenon Bachi nos alertam que já havia algumas revistas que informavam sobre o rádio, tais como $A$ voz do Rádio (1939) e Cinelândia (1939). Porém, não havia nenhuma que fosse estritamente especializada no assunto. Sendo assim, podemos arriscar dizer que a revista foi na época a referência

5 CHARTIER, Roger. "Defesa e ilustração da noção de Representação". In: Fronteiras, v. I3, n. 24, 20II, pp. 169-183.

6 Revista do Rádio, n. I, fevereiro de 1948.

190 • ano XI, n. 16, 2020 • ISSN 2179-5487 
principal de um periódico radiofônico. Ainda segundo as autoras: "A Revista do Rádio foi, assim, a primeira publicação especializada sobre este veículo. No início era mensal, mas, em menos de um ano, começou a circular semanalmente, tirando, em média, so mil exemplares". ${ }^{7}$

Imagem r: Capa da primeira edição da Revista do Rádio.

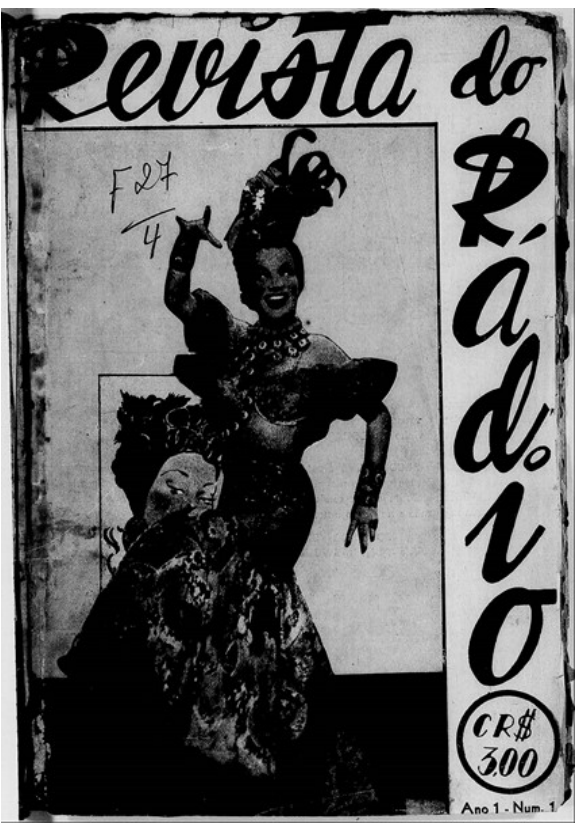

Fonte: Hemeroteca Digital da Biblioteca Nacional.

O destaque na revista fica para aquele ou aquela que fora estampada na capa. No caso da primeira edição, há uma longuíssima entrevista de Carmen Miranda, considerada na época a "Rainha do Rádio". Inclusive, é significativo ressaltar que a presença imagética daquela que era considerada uma das maiores cantoras de rádio na época e o quanto ela representava, com suas canções e vestimentas, aspectos de uma "nacionalidade" brasileira que estava muito alinhada com os debates que já ocorriam em pleno Estado Novo. Segundo Alessander Kerber, "ao mesmo tempo que Carmen tentava se apresentar como uma síntese do Brasil, era identificada como tal por amplos segmentos de seu público e, inclusive, contou, em certa medida, com o apoio do Estado para as representações que divulgava”. ${ }^{8}$

7 HAUSSEN, Doris Fagundes \& BACCHI, Camila Stefenon. "A Revista do Rádio através dos seus editoriais. (década de 5o)". In: Congresso Brasileiro de Comunicação, 24., 20oI. Campinas. Anais... Campinas: Sociedade Brasileira de Estudos Interdisciplinares da Comunicação, 2ooI, pp. I-Io. Citação à pág. 2.

8 KERBER, Alessander. "Carmen Miranda entre representações da identidade nacional e das identidades regionais”. In: ArtCultura, Uberlândia, v. 7, n. IO, 2005, pp. I2I-I32. Citação à pág. I2I. 


\section{REVISTA ANGELUS NOVUS}

E a revista prossegue com um editorial de Anselmo Rodrigues, já na terceira página, pequenas entrevistas de alguns artistas de rádio, programações de quase todas as rádios espalhadas pelo país, principalmente as que estavam localizadas no Rio de Janeiro e em São Paulo. Mas, não nos enganemos sobre estes aspectos. Sem um olhar atento, poderíamos pressupor que esta, assim como diversas outras revistas, serviria apenas para entretenimento. Ou seja, que os leitores desta revista se deparariam somente com notícias de cunho informativo sobre a vida privada e o universo dos artistas de rádio.

O que vislumbramos ao fazer uma análise, ainda que de caráter elementar, é que a revista informa sobre muito mais do que "fofocas" do rádio e seus envolvidos. Seguindo à risca o que a historiadora Ana Luiza Martins nos diz, que "texto, imagem, ilustrações, reclames e seções - em princípio, independentes de análise mais profunda - evocam em seu conjunto, de imediato, o quadro histórico em que se pretende transitar", tentaremos traçar algumas características, integradas em seu contexto histórico, que a revista nos releva para além do entretenimento.

Para exemplificar o que foi posto no parágrafo acima, temos, ainda na primeira edição da revista, um posicionamento bem claro de Anselmo Rodrigues acerca da criação da Associação Brasileira de Rádio, a qual fora criada no mesmo período que a revista e que, segundo o editor-chefe: "Já temos enfim o que se pode chamar de um órgão da classe. Resta que todos nós cooperemos. Não se pode compreender um radialista fora da associação (...) Hoje estamos orgulhosos da Associação Brasileira de Rádio”. ${ }^{\circ}$ Fofocas sobre artistas? Não apenas.

Arrisco dizer que Anselmo e toda sua equipe editorial na Revista do Rádio possuíam determinados interesses que correspondem a este "órgão da classe". Primeiramente, o de divulgar e tornar pública a criação desta associação, bem como o de opinar a respeito da adesão dos radialistas, visto que "não se pode compreender um radialista fora da associação”. Qual a importância atribuída pela revista à Associação? Quais os motivos que moveram a uma necessidade de organização associativa? Haveria algum ganho para os radialistas? E os radialistas leitores, quais os efeitos que surtiram ao se depararem com esta passagem?

Certamente o objetivo deste trabalho está um pouco distante de responder as perguntas que citei acima. Apenas procurei demonstrar, grosso modo, uma das diversas possibilidades que existem no que se refere ao ato de analisar uma revista que

9 MARTINS, A. L. "Da fantasia à História: folheando páginas revisteiras”. In: História. São Paulo, 22: 59-79, 2003, pp. 59-79. Citação à pág. 6o.

IO

Revista do Rádio, n. I, fevereiro de 1948.

I92 • ano XI, n. I6, $2020 \bullet$ ISSN 2179-5487 
comumente é conhecida como de entretenimento. Ou seja, que mesmo a Revista do Rádio tendo como princípio noticiar o que se passava nos bastidores do mundo radiofônico, ela não deixou de participar do debate político da época, seja internamente ao meio radiofônico (criação da Associação Brasileira de Rádio), seja para além do rádio, como nas eleições de I950. Pois "falar de política é uma coisa tão natural para um elemento de rádio como falar sobre o rádio para um elemento da política!”. "Natural? Logicamente, havia um jogo de interesses que circulava esta relação simbiótica entre rádio/política, e a revista aqui analisada revela de maneira contundente as opções e opiniões políticas dos trabalhadores do rádio.

Sendo assim, mesmo a revista servindo como meio informativo do ramo radiofônico, podemos, por meio dela, acompanhar os debates políticos nos quais estava inserida, podendo também escrever suas histórias e trajetórias. Ainda que Anselmo tenha dito que "um dia, se Deus quiser, contaremos a história da fundação da sociedade. Poderão contá-las igual a nós. Melhor não”. ${ }^{12}$ Gostaríamos, assim, de contar uma história política a partir da Revista do Rádio e de como ela evidencia questões para se pensar a atuação de diferentes atores, tanto aqueles que já estavam no ramo (Getúlio Vargas, por exemplos), como aqueles que estavam disputando um pleito (no caso, os inúmeros radialistas que se candidataram para cargos políticos).

\section{O retrato do "velho" voltou para o mesmo lugar ou nunca deixou de ter um "lugar"?}

Para fazer menção à marchinha de Haroldo Lobo, tomarei a mesma como medida introdutória, por duas razões: para explicar o título que subscreve esta seção, bem como para clarificar o universo cultural da época proposta para esta análise. A marchinha, que certamente embalou o carnaval de 195I, tinha por título "Bota o retrato do velho outra vez", e a seguinte letra:

Bota o retrato do velho outra vez

Bota no mesmo lugar

O sorriso do velbinho

Faz a gente trabalhar!

O retrato a que a canção se refere é aquele que era colocado em todas as repartições públicas durante o Estado Novo. Após a deposição de Vargas, em 1945, os retratos

II Revista do Rádio, n. 28, março de 1950.

I2 Revista do Rádio, n. I, fevereiro de 1948. 


\section{REVISTA ANGELUS NOVUS}

foram retirados. Com o retorno à presidência, os retratos voltariam para o mesmo lugar. No entanto, mesmo após o fim da ditadura estado-novista, existem fortes evidências de que Getúlio nunca deixou de ter um "lugar” no debate público e político. E sua imagem era lembrada e mobilizada nos mais diversos espaços.

Para dar exemplo desses espaços, temos a Revista do Rádio. Este semanário começou a circular em 1948, e já nos primeiros números da revista, vemos a menção do nome de Vargas sendo rememorado. ${ }^{13}$ No número 2 da revista, foram publicadas as seguintes frases: "Não há nada como um dia atrás do outro, lá diz o velho ditado. Naqueles bons tempos todo o mundo era getulista”. Nesta mesma publicação, há um retrato de Getúlio acompanhado de diversos artistas de rádio, o que muito chama a atenção, e que é uma regularidade em alguns números posteriores da revista, é o grande número de vezes em que o retrato de Vargas é colocado, ou o seu nome é mencionado, ou a sua fotografia é destacada. Concordando integralmente com a historiadora Tânia Regina de Luca, "a ênfase em certos temas, a linguagem e a natureza do conteúdo tampouco se dissociam do público que o jornal ou revista pretende atingir”. ${ }^{14}$

Junto a isso, podemos observar que a revista, alinhada política e ideologicamente à continuidade do projeto varguista, construiu de maneira positiva uma imagem de Vargas, antes mesmo das eleições de 1950. Nesse período, os editores investiram pesadamente em deixar claro o quanto estavam com saudades de Getúlio, ou o quanto queriam provocar este "sentimento" em seu público (e)leitor.

I3 Graças a um dispositivo de pesquisa de palavras-chave no site da Hemeroteca Digital, é possível localizar em quantas edições da revista aparece o nome de Getúlio. Aproximadamente 447 vezes, em um espaço temporal de 1948 a 1969 . Para este trabalho, foram considerados os números da revista onde é mencionado o nome de Vargas no que diz respeito à campanha eleitoral, tanto dele quanto dos radialistas que iriam também se candidatar para cargos políticos.

I4 LUCA, Tânia Regina de. "História dos, nos e por meio dos periódicos”. In: PINSKY, Carla. Fontes Históricas. São Paulo: Contexto, 2005, pp. III-I53. Citação à pág. I4O.

$194 \cdot$ ano XI, n. 16, $2020 \cdot \mathrm{ISSN} 2179-5487$ 
Imagem 2: Número I4, de abril de 1949.

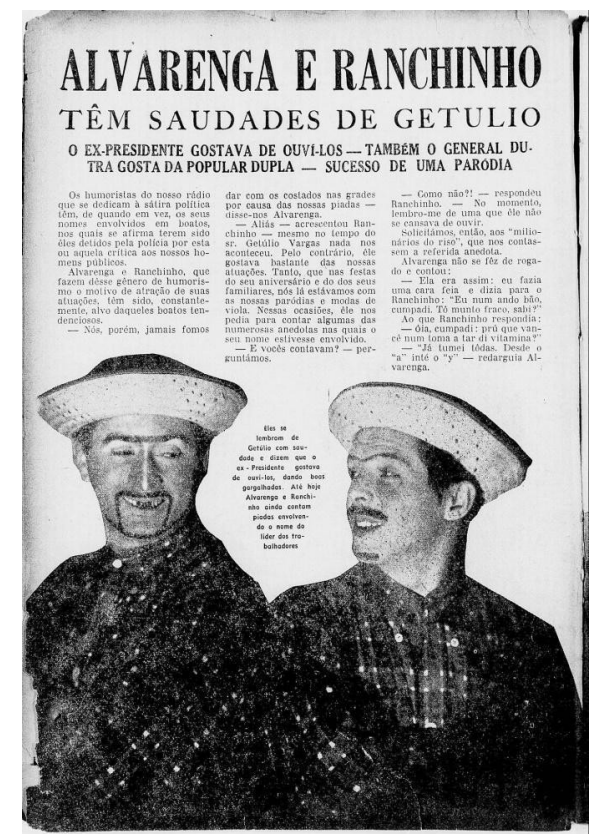

Fonte: Hemeroteca Digital da Biblioteca Nacional.

Mais interessante ainda são as colocações feitas em torno da figura de Vargas. A exemplo do número acima, Alvarenga e Ranchinho dizem em sua entrevista que nunca sofreram censura por conta de suas piadas, mesmo na época do Estado Novo. Pelo contrário, o próprio Getúlio os convidava para animar as festas do palácio do Catete, pois Getúlio “soltava muitas gargalhadas”.

Também são bastante recorrentes, ao longo das publicações, as vezes em que o nome de Getúlio aparece em entrevistas com artistas de rádio, alegando que nas eleições votariam nele, bem como o "bom humor" sendo o ponto explorado pela revista, talvez para dar conta de uma representação carismática do ex-ditador, que em pouco tempo se candidataria nas eleições e, com uma expressiva quantidade de votos, retornaria à presidência do país.

Na medida em que se aproxima o período eleitoral de I950, a revista não só amplia os números de páginas destinadas a discutir sobre política, como também demonstra certo apoio a Getúlio. Não de forma escancarada, mas de maneira sútil. Temos o exemplo de uma entrevista do radialista Silvino Neto, que, ao ser indagado a respeito das eleições, respondeu que "política é como futebol. Os melhores jogos são aqueles que tem a maior torcida. Na política, torcida é voto. Ninguém vai me dizer que Getúlio 


\section{REVISTA ANGELUS NOVUS}

não tenha uma força enorme por esses brasis eleitorais de meu Deus. Quem ele quiser será eleito!”. ${ }^{\text {'s }}$

São também estampadas diversas enquetes, que foram feitas pela revista de artistas de rádio, sobre em quem votariam nas eleições que estavam próximas. Quase que de forma unânime, todos concordavam que seu voto seria para Vargas. A revista não demonstrava de maneira enfática seu posicionamento político. No entanto, ao optar por divulgar as entrevistas onde a maioria das opiniões dos entrevistados são favoráveis ao Getúlio, a revista revelava qual projeto político apoiaria e quem, segundo a ótica dos editores do semanário, deveria estar na cadeira da presidência da República.

Imagem 3: Edição n. I7 da Revista do Rádio.

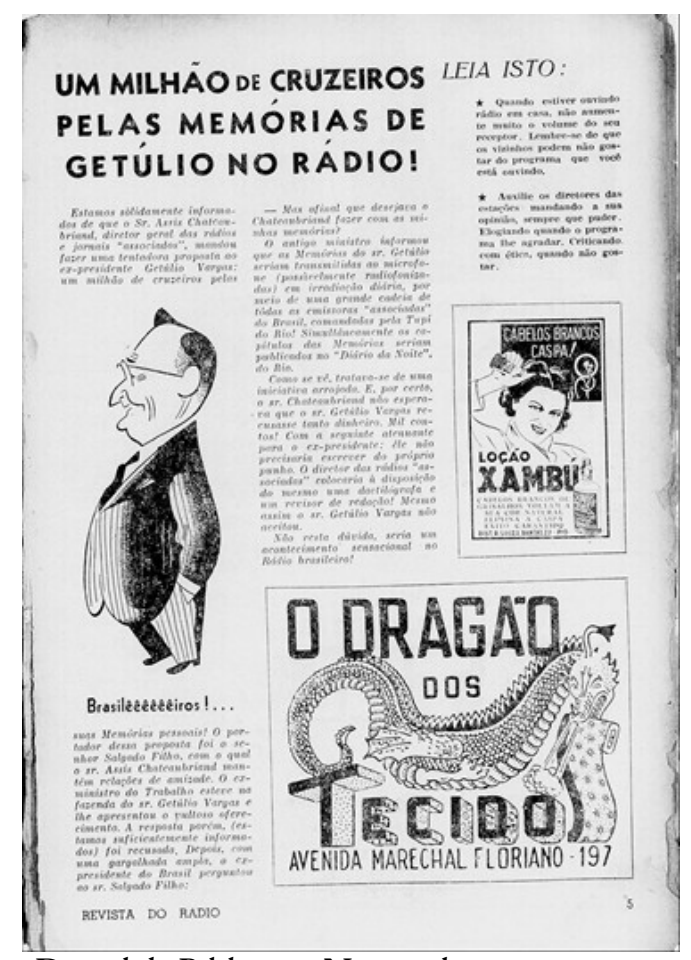

Fonte: Hemeroteca Digital da Biblioteca Nacional.

A imagem acima conta uma interessante história de um suposto empreendimento que seria realizado por Assis Chateaubriand, no ano de 1949. Chateaubriand havia solicitado que Salgado Filho, ex-ministro do Trabalho, fosse à fazenda de Vargas, em São Borja, para oferecer mil cruzeiros em troca de uma série de gravações das memórias de Getúlio, que seriam amplamente transmitidas nas emissoras “associadas”. Seguindo a reportagem: 
A resposta, porém, (estamos suficientemente informados) foi recusada. Depois, com uma gargalhada ampla, o ex-presidente do Brasil perguntou ao sr. Salgado Filho:

- Mas afinal, que desejava o Chateaubriand fazer com as minhas memórias? ${ }^{16}$

A proposta seguia com a condição de que Vargas não precisaria escrever de próprio punho. Haveria um datilógrafo disponível, assim como um revisor de redação. A oferta foi recusada e, ainda sim, foi tomada como uma notícia digna de gravura! Tratando-se dela, é a primeira vez que Getúlio aparece "representado" na revista. Muito nos chama a atenção o efeito sombreado e as curvas que remetem a um "senhor de idade", bemvestido, com a mão no bolso, demonstrando destreza, confiança.

Uma imagem intimista, por assim dizer. Com um sorriso entreaberto. Inclusive, os próprios redatores da reportagem fizeram questão de dizer que a recusa viera de Getúlio com "uma gargalhada ampla". Aos poucos, vemos que a revista contribuiu para mobilizar e construir simbolicamente uma imagem positiva do então conhecido como “pai dos pobres”, ou nesse caso, "amigo dos artistas".

Após a vitória de Getúlio nas urnas, como já citamos, Haroldo Lobo escreveu uma marchinha para o carnaval daquele ano, onde dizia que "o sorriso do velhinho faz a gente trabalhar". Como vemos, o sorriso de Vargas era extremamente requisitado. Não só isso, mas também construído, mobilizado pela imprensa, principalmente pela Revista do Rádio, sob o intuito de transformá-lo em algo simbólico. Isso pode ser comprovado ainda na edição sobre as memórias de Getúlio, onde a reportagem diz que "não resta dúvida, seria um acontecimento sensacional no Rádio Brasileiro!”. ${ }^{7}$

Podemos dizer que esta matéria, acompanhada da gravura de Getúlio, e seu sorriso sendo evocado mesmo tendo recusado a oferta, acabou tornando esta singela reportagem em um espaço de memória. A memória do sorriso, da espirituosidade, que está arraigada nos traços da gravura. A memória de Vargas não foi irradiada, mas sua imagem se fez presente na revista, tornou-se lembrança, e, propositalmente, fora mobilizada de forma a garantir que os (e)leitores não se esquecessem do "sorriso do velhinho".

\section{Getúlio e os radialistas políticos}

Cabe aqui, talvez, perguntarmo-nos quais as motivações que levavam a Revista do Rádio a demonstrar um amplo apoio a Vargas, bem como a tornar públicos os

I6 Revista do Rádio, n. I7, julho de 1949.

I7 Revista do Rádio, n. I7, julho de 1949. 


\section{REVISTA ANGELUS NOVUS}

posicionamentos políticos dos radialistas. No ano de 1950, principalmente no período que antecedeu as eleições, a revista publicou uma série de entrevistas com os políticos radialistas. A título de exemplo, há uma entrevista que foi estampada no número 55, de 26 de agosto de 1950, com Cesar Moreno. Nela, é feita uma pergunta que foi elencada em praticamente todas as entrevistas, quanto a se havia a crença por parte dos entrevistados de que "o rádio poderia dar mais de um candidato". Havia um consenso de que não só poderia dar mais de um candidato, como também quantos mais o "povo quiser colocar". ${ }^{18}$

Anselmo escreve que "não há dúvida da popularidade que o Rádio dá. E, cientes dela, mais do que todos, estão os próprios elementos que no Rádio labutam”. ${ }^{19}$ E, a partir da constatação da popularidade proporcionada aos trabalhadores do rádio, alguns, antes de 1950, já tinham se candidatado, como no caso de Ary Barroso, "que naquela ocasião não desfrutava da antiga simpatia entre o público, alcançou um número de votos que a muitos surpreendeu. Coisas do rádio, da popularidade que ele dá, da fascinação pelos seus artistas, pelos seus nomes”. ${ }^{20}$

Anselmo também informa aos leitores que identificou cerca de II possíveis candidatos do rádio. Dentre eles, temos: Paulo Gracindo, Aloisio Silva Araújo, Júlio Louzada, Edgard de Carvalho, Cesar Ladeira, Jorge Veiga, Carlos Frias, Sagramor Severo, Badú, Ari Barroso e Vitor Costa. E, ao longo do desenrolar do período eleitoral, a revista publicou uma série de entrevistas com estes candidatos, onde se constata o apoio a Getúlio Vargas, ou a quem ele decidir apoiar.

Podemos dizer, provisoriamente, que este apoio certamente foi imprescindível para que os "campeões do microfone" fossem também campeões nas urnas. Podemos também concluir, seguindo a ótica dos radialistas, que "dizem que Getúlio Vargas, de todos presidentes, é o amigo dos artistas brasileiros. E é verdade. Verdade é também que os artistas são os maiores amigos de Vargas. Tanto que já está provado que fomos nós que lhe demos a vitória!”. ${ }^{21}$

Para corporificar como os artistas de rádio estavam apoiando Vargas nas eleições de I950, caminharei na esteira de uma pesquisa feita por Carla Montuori Fernandes, sobre

I8 Cesar Moreno responde da seguinte maneira "Como não? O rádio possui culturas sólidas, inteligências vivas e patriotas devotados. E o povo sabe disso". Nos chama atenção a relação do "povo" como ouvinte de radialistas com forte "potencial" para representar politicamente o tal "povo".

19 Revista do Rádio, n. 28, março de 1950.

20 Revista do Rádio, n. 28, março de 1950.

2I Revista do Rádio, n. 68, dezembro de 1950.

$198 \cdot$ ano XI, n. I6, $2020 \cdot \mathrm{ISSN} 2179-5487$ 
a campanha presidencial de Getúlio e seu apoio junto à classe radiofônica, que diz o seguinte:

O apoio a Getúlio Vargas pode ser verificado nas respostas de inúmeros artistas ao longo da reportagem. $\mathrm{O}$ ator Paulo Gracindo declarou que votaria no nome que seu partido, o PTB, indicasse para presidente. $\mathrm{O}$ popular comediante Matinhos respondeu à enquete exclamando: “Getúlio! Getúlio e Getúlio!”. César de Barros Barreto, diretor do Departamento de Rádio da Sidney Ross, também manifestou sua preferência pelo candidato do PTB: "Votarei em Getúlio Vargas!". O rádio-ator pertencente ao "cast” da Rádio Nacional, Castro Viana, não demorou em afirmar: "Votarei em Getúlio e acho que estarei votando bem, porque Getúlio já fez prova de suficiência como presidente da República e depois, vamos dizer como Bernard Shaw: 'Se o povo prefere Getúlio, para que discutir com o povo?!”. .22

Todas as menções, fotografias, imagens e gravuras de - e sobre - Getúlio Vargas criaram uma narrativa que, ao mesmo tempo em que entregava o alinhamento ideológico dos editores da revista, também surtia, provavelmente, um efeito positivo sobre aqueles que liam as reportagens, que eram certamente bombardeados pelo nome mais aclamado do semanário. Obviamente, não é possível saber, de fato, como foi a recepção dessas reportagens pelo público leitor. No entanto, o que se revela, talvez, são as possíveis razões da classe radiofônica para apoiar veementemente o retorno de Vargas à presidência.

22 FERNANDES, Carla Montuori; CHAGAS, Genira Correia; DIAS, Carla. "Resistência e popularidade na campanha presidencial de 1950: o retorno de Getúlio Vargas à Presidência da República”. In: ECCOM, v. 9, n. 17, jan./jun. 2018, pp. 139-150. Citação à pág. I45. 
Imagem 4: Número 37, de 23 de maio de 1950.

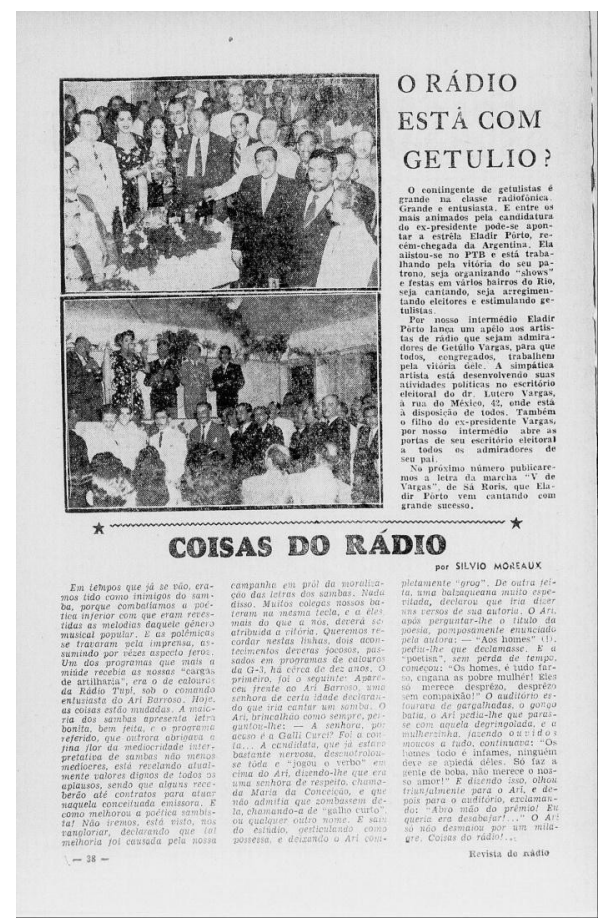

Fonte: Hemeroteca Digital da Biblioteca Nacional.

Ao longo do ano de 1950, a revista se deteve na seguinte indagação: o rádio está com Getúlio? Paralelamente a este “autoquestionamento”, o semanário dedicou uma parte significativa de seus números a comentar a respeito dos inúmeros radialistas que, nas eleições que se aproximavam, iriam se candidatar. Quase todos esses radialistas ou eram apoiadores ferrenhos de Vargas, ou estavam vinculados ao Partido Trabalhista Brasileiro (PTB). Não se precisa ir muito longe para ver que, escancaradamente, o rádio não só estava com Getúlio, como faria qualquer coisa para que retornasse à presidência.

\section{Considerações finais}

Ainda é incipiente estabelecer de maneira profícua como de fato era tecida a relação entre radialistas e Vargas. No entanto, o que se pode demonstrar por meio das representações geradas pela Revista do Rádio sobre Getúlio é que havia uma imagem precisa e positiva de Vargas. E esta imagem era mobilizada de acordo com os interesses específicos, em primeiro lugar, dos editores da revista, e, em segundo lugar, daqueles que iriam se candidatar. Logo, este suposto carisma e "bom humor" não tinha um fim em si mesmo. Possuía a finalidade de garantir que os leitores poderiam ser persuadidos, 
tanto por essa figura, como pela boa relação que havia entre Getúlio e os radialistas políticos, o que poderia garantir tanto a vitória na presidência quanto nas câmaras estaduais e municipais. Ambos sairiam ganhando.

A Revista do Rádio apresenta em seus editoriais o seu apoio político a Vargas, e por que não dizer que este apoio contribuiu para que o ex-ditador chegasse novamente ao cargo de presidente? A revista acompanhou de perto, sobretudo, as eleições que trouxeram Vargas novamente à presidência, estampou entrevistas com artistas que se consideravam varguistas, caricaturou Getúlio com seu irreverente sorriso, e assim apoiou veementemente que o "retrato do velho fosse colocado outra vez". O retrato foi colocado outra vez no mesmo lugar, e novos retratos estavam dinamizando e diversificando o quadro político da República que fora chamada e aclamada como "democrática". 